\title{
Cardiac Arrest - Cardiopulmonary Resuscitation
}

Basri Lenjani ${ }^{1 *}$, Kelmend Pallaska ${ }^{1}$, Kadir Hyseni ${ }^{2}$, Nexhbedin Karemani ${ }^{2}$, llaz Bunjaku ${ }^{3}$, Taxhidin Zaimi ${ }^{3}$ and Besnik Elshani ${ }^{3}$

${ }^{1}$ Emergency Clinic, University Clinical Centre of Kosovo, Pristina 10000, Republic of Kosovo

${ }^{2}$ Anesthesiology Clinics, University Clinical Centre of Kosovo, Pristina 10000, Republic of Kosovo

${ }^{3}$ Radiology Clinic, University Clinical Centre of Kosovo, Pristina 10000, Republic of Kosovo

\begin{abstract}
Introduction: Every year about 500,000 people in Europe are victims of cardiac arrest. Cardiopulmonary resuscitation (CPR) implemented by lay persons in outpatient settings increased facing the survival rate for 2-3 times, if applicable in outpatient settings. Application of CPR measures within the golden minutes in Europe, may save the lives of about 100000 persons per year.
\end{abstract}

Objective: To investigate application of cardiopulmonary resuscitation (CPR) measures within the golden minutes in Europe.

Aim: The main Purpose of this paper is to present the treated cases with cardiac arrest in the Emergency Centre of the University Clinical Centre of Kosovo and (CUCK).

Methods: The material is taken from the University Clinical Center of Kosovo - Emergency Centre in Pristina, during the two (2) year period (2010-2011). The Collected date belong to the patients with cardiac arrest have been recorded in the patients' log book protocol at the Emergency Clinic.

Results and conclusions: During the 2010 to 2011 in the Emergency Center of the CUCK in Pristina have been treated a total of 269 patients with cardiac arrest, of whom 159 or $59.1 \%$ have been treated in 2010 , and 110 patients or $40.9 \%$ in 2011. Of the 269 patients treated in the Emergency Centre, 93 or $34.6 \%$ have exited lethally in the Emergency Centre, and 176 or $65.4 \%$ have been transferred to other Clinics. In the total number of patients with cardiac arrest, males have dominated with 186 cases, or $69.1 \%$. The average age of patients included in the survey was 56.7year old (SD \pm 16.0 years. Of the 269 patients with Cardiac arrest, defibrillation has been applied for 93 or $34.6 \%$ of patients. In the outpatient settings defibrillation has been applied for 3 or $3.2 \%$ of patients. Patients were defibrillated with application of one to four shocks. Of 27 cases with who have survived cardiac arrest, none of them have suffered cardiac arrest at home, 3 or $11.1 \%$ of them have suffered cardiac arrest on the street, and 24 or $88.9 \%$ of them have suffered cardiac arrest in the hospital. 5 out of 27 patients survived have ended with neurological impairment.

Conclusions: Cardiac arrest cases were present during all days of the week, but frequently most reported cases have been on Monday with $32.0 \%$ of cases, and on Friday with $24.5 \%$ of cases. All survivors from cardiac arrest have received appropriate medical assistance within 10 minutes from attack, which implies that if cardiac arrest occurs near an institution health care (with an opportunity to provide the emergent health care) the rate of survival is higher.

Keywords: Cardiac arrest; Emergency center; Cardiopulmonary resuscitation; Bradyrhythmia; Tachyarrythmia

\section{Introduction}

Cardiac arrest is the cessation of cardiac mechanical activity, confirmed by the lack of pulse, respiration, and loss of consciousness. Most of the cases with cardiac arrests in the hospital are originated from the heart. There is not, however, over-estimated the arrest report originated from, if it is not confirmed by autopsy. Each year about 500,000 people in Europe are victims of cardiac arrest. CPR applied by laymen survival rate increases to 2-3 times, if applied in outpatient settings. The implementation of CPR measures within golden minutes in Europe may save lives 100,000 persons per year. In Europe every 45 seconds happen a cardiac arrest. Quick rescutitation and early defibrillation (within 1-2 minutes) can increase survival > $60 \%$. In Kosovo during a year we have 4000-5000 every year in an hour a cardiac arrest occurs within $24 \mathrm{~h} 13.7$ cases are presented. In Kosovo every 1:51 minute a cardiac arrest occurs. If CPR is applied within minutes golden, the survival of victims will reach $34 \%$, compared with the 2005 CPR guidelines, which survival amounts to $18 \%$ of victims. These data come from the new guidelines from the "American Heart Association 2010" Under this amended standard procedures by $\mathrm{ABC}$ (Airways, Breathing-Compressions) apply and vary actions, "ABC to "CAB" (Compressions-Airways-Breathing ). Savior who are trained and ready to make the move, cardiac massage can be combined with artificial respiration, in the ratio of 30 pressures in the chest and two life-breath [1-3]. Basic life support - Basic life support (BLS) is the fundamental basis for life-saving cardiac arrest victims after as to (illnesses, injuries and poisonings) BLS fundamental aspects include: Early recognition of sudden cardiac arrest, Activation of the emergency response system, Early CPR, Rapid defibrillation (AED) [4]. Two main steps of saving lives: Medical Emergency 112 Call, Press quickly strong in the center of the chest. Quality of CPR-BLS - in outpatient and inpatient settings to victims of cardiac arrest is often weak in most cases, and should develop methods to improve the quality of CPR, particularly in Kosovo conditions. Advanced Cardiac Life Support (ACLS) - ACLS interventions intended to prevent cardiac arrest in particular by include: managing the respiration, ventilation support,

*Corresponding author: Basri Lenjani, University Clinic, Clinical Emergency, Center of Kosovo, Pristina, Kosovo, Tel: +377 44165770; E-mail: basrilenjani@yahoo.com

Received August 21, 2013; Accepted January 21, 2014; Published February 03 , 2014

Citation: Lenjani B, Pallaska K, Hyseni K, Karemani N, Bunjaku I, et al. (2014) Cardiac Arrest - Cardiopulmonary Resuscitation. Gen Med (Los Angel) 2: 131. doi: 10.4172/2327-5146.1000131

Copyright: @ 2014 Lenjani B, et al. This is an open-access article distributed under the terms of the Creative Commons Attribution License, which permits unrestricted use, distribution, and reproduction in any medium, provided the original author and source are credited. 
handling bradyrhythmia and tachyarrythmia. Advanced Cardiac Life Support - ACLS, which administered medications, cardiac monitoring and other technical-medical [5].

\section{Research Puropses}

The main purpose of this paper to reduce the incidence, longevity and mortality of persons from cardiac arrest in the street, at home and in hospital environments for the implementation of early fast intervention of CPR to save people's lives with life threatening. The implementation of Basic Life Support (BLS) and learn how to work Advanced Cardiac Life Support (ALCS) is the fundamental purpose of saving the lives of victims with cardiac arrest [6].

\section{Materials and Methods}

The material is taken from the University Clinical Center of Kosovo - Emergency Clinic in Prishtina on two-year period 2010-2011. The data were derived from the protocol of the Emergency Clinic patients with cardiac arrest patients [7]. There are investigated only patients with cardiac arrest origined cardiac. Purpose is realized on the basis of: the anamnesis, vital status parameters, objective examination results, diagnostic research - laboratory and radiology, statistical parameters, the index structure, and the arithmetic average and standard deviation. Statistical tests: X2-test and T-tests. Test verification is made for $95 \%$ confidence level and $99 \%$, respectively $p<0: 01$ and $p<0: 05$ [8].

\section{Results}

In the UCC Emergency Clinic in Prishtina during 2010-2011 were treated 269 patients with cardiac arrest from which 159 or $59.1 \%$ were treated in 2010 while 110 or $40.9 \%$ in 2011 (Table 1).

The average age of the patients included in the survey was 56.7 years ( $\mathrm{SD} \pm 16.0$ years), the youngest patient was under 1 year and the oldest 92 years (Table 2 ).

The average age of female patients included in the survey was 55.2 years ( $\mathrm{SD} \pm 14.6$ years), the youngest patient was 20 years and the oldest 92 years. The average age of male patients included in the survey was 57.3 years ( $\mathrm{SD} \pm 16.6$ years), the youngest patient was under 1 year and the oldest 87 years. T-test averages have not earned the distinction with important statistically significant between the average age by gender $(\mathrm{t}$ $=0.99, \mathrm{P}>0: 05)$ [9-11] (Table 3). As shown in Table 5 we had only one case or $0.4 \%$ children less than one year, two cases or $0.7 \% 1-6$ years, 1

\begin{tabular}{|c|c|c|}
\hline Year & N & $\%$ \\
\hline 2010 & 159 & 59.1 \\
\hline 2011 & 110 & 40.9 \\
\hline Total & 269 & 100.0 \\
\hline
\end{tabular}

Table 1: Number of patients with cardiac arrest in years.

\begin{tabular}{|c|c|c|c|}
\hline \multirow{2}{*}{ Age } & $\mathbf{2}$ & Sex & Total \\
\hline $\mathrm{N}$ & 83 & $\mathbf{M}$ & 269 \\
\hline Average & 55.2 & 57.3 & 56.7 \\
\hline DS & 14.6 & 16.6 & 16.0 \\
\hline Min & 20 & 1 & 1 \\
\hline Max & 92 & 87 & 92 \\
\hline T-test, P-value & \multicolumn{2}{|c|}{$\mathrm{T}=0.99, \mathrm{P}>0: 05$} & \\
\hline
\end{tabular}

Table 2. Parameters age of the patients by gender

\begin{tabular}{|c|c|c|c|c|c|c|}
\hline & \multicolumn{9}{|c}{ Sex } & \multicolumn{2}{c|}{ Total } \\
\hline Age-group & \multicolumn{2}{|c|}{ F } & \multicolumn{2}{|c|}{ M } & N & $\%$ \\
\hline & N & $\%$ & N & $\%$ & 1 & 0.4 \\
\hline $1-6$ & - & - & 1 & 0.5 & 1 & 0.7 \\
\hline $7-18$ & - & - & 2 & 1.1 & 2 & 0.4 \\
\hline $19-64$ & 60 & 72.3 & 117 & 62.9 & 177 & 65.8 \\
\hline $65+$ & 23 & 27.7 & 65 & 34.9 & 88 & 32.7 \\
\hline Total & 83 & 100.0 & 186 & 100.0 & 269 & 100.0 \\
\hline
\end{tabular}

Table 3. Patients with cardiac arrest by age group and sex.

\begin{tabular}{|c|c|c|}
\hline Heart rate & N & $\%$ \\
\hline TV & 20 & 7.4 \\
\hline FV & 39 & 14.5 \\
\hline Assis & 193 & 71.7 \\
\hline (PEA) & 17 & 6.3 \\
\hline Total & 269 & 100.0 \\
\hline
\end{tabular}

Table 4. Pathophysilogy forms of presentation in early ECG CPR procedures.

\begin{tabular}{|c|c|c|}
\hline Defibrillation & N & $\%$ \\
\hline In outpatient settings & 3 & 3.2 \\
\hline In hospital environments UCC CEO & 90 & 96.8 \\
\hline In total & 93 & 100.0 \\
\hline
\end{tabular}

Table 5. The number of patients defibrillated in outpatient settings and hospital environments.

\begin{tabular}{|c|c|c|}
\hline Number of hits friend & N & $\%$ \\
\hline $1 \times$ DC & 20 & 21.5 \\
\hline $2 \times$ DC & 38 & 40.9 \\
\hline $3 \times$ DC & 22 & 23.7 \\
\hline 4 x DC & 13 & 14.0 \\
\hline Total & 93 & 100.0 \\
\hline
\end{tabular}

Table 6. Defibrilliation number of actions during CPR measures.

\begin{tabular}{|l|c|c|}
\hline CPR & N & $\%$ \\
\hline In hospital environments & 243 & 90.3 \\
\hline In outpatient settings & 3 & 1.1 \\
\hline Not CPR & 37 & 13.8 \\
\hline In total & 269 & 100.0 \\
\hline
\end{tabular}

Table 7. The number of patients in whom CPR measures are implemented.

case or $0.4 \%$ of the age group $7-18$ years, 177 cases or $65.8 \%$ of $19-64$ years age group and 88 cases or $32.7 \%$ were 65 or more years. Children with cardiac arrest have been only males, while patient females were adult $19-64$ years $72.3 \%$ and 65 or more years 23 or $27.7 \%$ [12].

In early cardiopulmonary resuscitation procedures we had 20 patients or $7.4 \%$ of all patients with ventricular tachycardia, 39 or $14.5 \%$ with ventricular fibrillation, 193 or $71.7 \%$ of Asystole and 17 or $6.3 \%$ with no pulse electrical activity (electromechanical dissociation) [13] (Table 6). At the end of the CPR procedures we had 26 patients or $9.7 \%$ of all patients with ventricular tachycardia, 34 or $12.6 \%$ with ventricular fibrillation, 168 or $62.5 \%$ of Asystole, 14 or $5.2 \%$ of electrical activity without pulse and 27 or $10.0 \%$ the normal rythm (Table 7). Of 269 patients with cardiac arrest defribillation is applied to 93 or $34.6 \%$. In outpatien settings defribillation is made to three or $3.2 \%$ of patients [14] (Table 4).

Cardiopulmunary resuscitation of 243 patients or $90.3 \%$ is applied 


\begin{tabular}{|c|c|c|}
\hline Country & N & $\%$ \\
\hline Back home & 0 & 0 \\
\hline Street & 3 & 11.1 \\
\hline Hospital & 24 & 88.9 \\
\hline In total & 27 & 100.0 \\
\hline
\end{tabular}

Table 8. The number of survivors of cardiac arrest at home sick, roads and hospital.

\begin{tabular}{|l|c|c|}
\hline Days of the Week & N & $\%$ \\
\hline Monday & 86 & 32.0 \\
\hline Tuesday & 25 & 9.3 \\
\hline Wednesday & 34 & 12.6 \\
\hline Thursday & 29 & 10.8 \\
\hline Friday & 66 & 24.5 \\
\hline Saturday & 26 & 9.7 \\
\hline Sunday & 23 & 8.6 \\
\hline In total & 269 & 100.0 \\
\hline \multicolumn{2}{|c|}{ Table 9: Cardiac arrest occurred by days of the week. } \\
\hline
\end{tabular}

in hospital environments, to 3 or $1.1 \%$ is applied in outpatient settings and 37 or $13.8 \%$ is applied cardiopulmonary resusciation [15] (Table 5).

The defribilliated patiens are applied from a shock stroke to four shock strokes [16]. A shock stroke is applied to 20 patients or $21.5 \%$, two shock strokes to 38 or $40.9 \%$, three shock strokes to 22 or $23.7 \%$ and four shock strokes to 13 or $14.0 \%$ (Table 6).

Cardiopulmonary resuscitation of 243 patients or $90.3 \%$ is applied in hospital environments, to 3 or $1.1 \%$ is applied in outpatient settings and 37 or $13.8 \%$ is applied cardiopulmonary resusciation (Table 7). In our clinical material 242 or $90.0 \%$ of the patients were endotracheal Intubation. The four patients or $1.5 \%$ endotracheal intubation is made in outpatient settings, the 238 or $88.5 \%$ in hospital environment (from 269193 patients with cardiac arrest or $71.7 \%$ came in emergency wthout life-signs, and 76 or $28.3 \%$ of patients had pupil-dilated less than $4 \mathrm{~mm}$ [17].

At the end of treatment in UCC 242 patients or $90.0 \%$ are fatal, whereas only 27 patients or $10.0 \%$ survive. Those survivors of cardiac arrest have received adequate medical aid within 10 minutes after the attack. Out of the total number 3 or $11.1 \%$ were treated within the first and second minutes after the attack, 21 or $77.8 \%$ in the third minute and the fourth and three others from the fifth minute to ten minutes after the attack [18]. There were no survivors when medical aid is provided later.Of the 27 cases of cardiac arrest survivors none of them had cardiac arrest at home, 3 or $11.1 \%$ had cardiac arrest in the street and 24 or $88.9 \%$ had cardiac arrest in hospital [19]. Which means that if the cardiac arrest occurs near health institution (ability to give emergency aid) survival rate is higher (Table 8). As shown in Table 8, the 27 survivors 5 or $18.5 \%$ have completed neurological damage.

Cases with cardiac arrest has had on all days of the week but mostly there was on Monday with $32.0 \%$ of cases, then on Friday with $24.5 \%$ while other days is similar and ranges from $12.6 \%$ on Wednesday, $10.8 \%$ on Thursday, $9.7 \%$ on Saturday, $9.3 \%$ on Tuesday and $8.6 \%$ on Sunday (Table 9).

\section{Discussion and Conclusions}

Cardiac arrest is the leading cause of sudden death. The implementation of CPR measures within the gold miutes in Europe may save lives of 100,000 people in a year [20-22]. In Helsinki, Finland, 67\% of all cardiac arrest with cardiac origin are verified by autopsy. $90 \%$ of cardiac arrests occured in Sweden, are cardiac origin, as a result of ischemic heart disease, while $10 \%$ are due to heart disease and other diseases, such as valvular or cardiomyopathy. In Kosovo within a year there are 40005000 every one hour a cardiac arrest occurs and within 24 hours occur to 13.7 cases. In Kosovo every 1:51 minute occurs a cardiac arrest. Cardiac arrest in outpatient settings in Kosovo is more common among different age group, with very high mortality results [4]. Women who suffer from cardiac arrest increases about 29\% share, the mortality rate in Europe is still high $[1,3,4]$. Therefore, strict implementation of the new CPR recomandation will significantly help to reduce disability and mortality in Kosovo [23-25]. Whereas in America and Europe is significantly lower. In America and Europe disability and mortality from cardiac arrest is lower in comparison with Kosovo. While the developed countries like America, Sweden, Australia, France, Germany etc. economically well developed, have invested in legislation regulating care emergency medical services in outpatient settings and hospital environment [26]. This has affected the provision of medical services for emergent medical supplies and education and training and education of nurses and doctors as well as population. But in Kosovo emergency medical services are developing and in the future remains to be emergency medical services priority to Ministry of Health and the Government of Kosovo. For this reason emergency medical services to us and in Europe do not generate revenue but to persons escape danger [27].

\section{Recommendations}

Support, advancement and empowerment of the SHEM by the Ministry of Health in three levels of organisation of the health system to support these directions as in : Advancement and empowerment of emergency medical services and hospital environment and outpatient settings. Establishing standards for ambulances For ex SHEM outpatient settings. Establishing long-term policies and strategies for SHEM. Education and continuous training of staff in emergency outpatient settings and hospital environments. Establishing protocols, algorithms and guide clinic Formation of cardiac medical teams and hospital environment and outpatient settings. To encourage and develop emergency medical services as an integral part of the unique health system [28]. The goals of the national program models SHEM, which are mandatory to be regulated through legislation and laws to be implemented.

\section{References}

1. Hüpfl M, Selig HF, Nagele $P$ (2010) Chest-compression-only versus standard cardiopulmonary resuscitation: a meta-analysis. Lancet 376: 1552-1557.

2. Berg RA, Hemphill R, Abella BS, Aufderheide TP, Cave DM, et al. (2010) Part 5: adult basic life support: 2010 American Heart Association Guidelines for Cardiopulmonary Resuscitation and Emergency Cardiovascular Care. Circulation 122: S685-705.

3. Ogawa T, Akahane M, Koike S, Tanabe S, Mizoguchi T, et al. (2011) Outcomes of chest compression only CPR versus conventional CPR conducted by lay people in patients with out of hospital cardiopulmonary arrest witnessed by bystanders: nationwide population based observational study. BMJ 342: c7106.

4. Vanden Hoek TL, Morrison LJ, Shuster M, Donnino M, Sinz E, et al. (2010) Part 12: Cardiac Arrest in Special Situations: 2010 American Heart Association Care Guidelines for Cardiopulmonary Resuscitation and Emergency Cardiovascular Care. Circulation 122: S819-S851.

5. Field JM, Hazinski MF, Sayre MR, Chameides L, Schexnayder SM, et al. (2010) Part 1: Executive Summary: 2010 American Heart Association Guidelines for Cardiopulmonary Resuscitation and Emergency Cardiovascular Care. Circulation 122: S640-S650.

6. Sayre MR, O'Connor RE, Atkins DL, Billi JE, Callaway CW, et al. (2010) Part 2: Evidence Evaluation and Management of Potential or Perceived Conflicts Resuscitation and Emergency Cardiovascular Care of Interest: 2010 American Heart Association Guidelines for Cardiopulmonary Resuscitation and Emergency Cardiovascular Care. Circulation 122: S657-S664. 
Citation: Lenjani B, Pallaska K, Hyseni K, Karemani N, Bunjaku I, et al. (2014) Cardiac Arrest - Cardiopulmonary Resuscitation. Gen Med (Los Angel) 2: 131. doi: 10.4172/2327-5146.1000131

7. Morrison LJ, Kierzek G, Diekema DS, Sayre MR, Silvers SM, et al. (2010) Part 3: Ethics: 2010 American Heart Association Guidelines for Cardiopulmonary Resuscitation and Emergency Cardiovascular Care. Circulation 122: S665-S675.

8. Travers AH, Rea TD, Bobrow BJ, Edelson DP (2010) Part 4: CPR Overview: 2010 American Heart Association Guidelines for Cardiopulmonary Resuscitation and Emergency Cardiovascular Care. Circulation 122: S676-S684

9. Berg RA, Hemphill R, Abella BS, Aufderheide TP, Cave DM, et al. (2010) Part 5: Adult Basic Life Support: 2010 American Heart Association Guidelines for Cardiopulmonary Resuscitation and Emergency Cardiovascular Care. Circulation 122: S685-S705.

10. Link MS, Atkins DL, Passman RS, Halperin HR, Samson RA, et al. (2010) Part 6: Electrical Therapies: Automated External Defibrillators, Defibrillation, Cardioversion, and Pacing: 2010 American Heart Association Guidelines for Cardiopulmonary Resuscitation and Emergency Cardiovascular Care. Circulation 122: S706-S719.

11. Cave DM, Gazmuri RJ, Otto CW, Nadkarni VM, Cheng A, et al. (2010) Part 7: CPR Techniques and Devices: 2010 American Heart Association Care Guidelines for Cardiopulmonary Resuscitation and Emergency Cardiovascular Care. Circulation 122: S720-S728

12. Neumar RW, Otto CW, Link MS, Kronick SL, Shuster M, et al. (2010) Part 8: Adult Advanced Cardiovascular Life Support: 2010 American Heart Cardiovascular Care Association Guidelines for Cardiopulmonary Resuscitation and Emergency Cardiovascular Care. Circulation 122: S729-S767.

13. Peberdy MA, Callaway CW, Neumar RW, Geocadin RG, Zimmerman JL, et al. (2010) Part 9: Post-Cardiac Arrest Care: 2010 American Heart Association Guidelines for Cardiopulmonary Resuscitation and Emergency Cardiovascular Care. Circulation 122: S768-S786.

14. O'Connor RE, Brady W, Brooks SC, Diercks D, Egan J, et al. (2010) Part 10 Acute Coronary Syndromes: 2010 American Heart Association Care Guidelines for Cardiopulmonary Resuscitation and Emergency Cardiovascular Care. Circulation 122: S787-S817.

15. Jauch EC, Cucchiara B, Adeoye O, Meurer W, Brice J, et al. (2010) Part 11 Adult Stroke: 2010 American Heart Association Guidelines for Cardiopulmonary Resuscitation and Emergency Cardiovascular Care. Circulation 122: S818-S828.

16. Vanden Hoek TL, Morrison LJ, Shuster M, Donnino M, Sinz E, et al. (2010) Part 12: Cardiac Arrest in Special Situations: 2010 American Heart Association Care Guidelines for Cardiopulmonary Resuscitation and Emergency Cardiovascular Care. Circulation 122: S829-S861.
17. Berg MD, Schexnayder SM, Chameides L, Terry M, Donoghue A, et al. (2010) Part 13: Pediatric Basic Life Support: 2010 American Heart Association Care Guidelines for Cardiopulmonary Resuscitation and Emergency Cardiovascular Care. Circulation 122: S862-S875.

18. Bhanji F, Mancini ME, Sinz E, Rodgers DL, McNeil MA, et al. (2010) Part 16: Education, Implementation, and Teams: 2010 American Heart Cardiovascular Care Association Guidelines for Cardiopulmonary Resuscitation and Emergency Cardiovascular Care. Circulation 122: S920-S933.

19. Peberdy MA, Callaway CW, Neumar RW, Geocadin RG, Zimmerman JL, et al. (2010) Part 9: Post-Cardiac Arrest Care 2010 American Heart Association Guidelines for Cardiopulmonary Resuscitation and Emergency Cardiovascular Care. Circulation 122: S768-S786.

20. Vanden Hoek TL, Morrison LJ, Shuster M, Donnino M, Sinz E, et al. (2010) Part 12: Cardiac Arrest in Special Situations: 2010 American Heart Association Care Guidelines for Cardiopulmonary Resuscitation and Emergency Cardiovascular Care. Circulation 122: S829-S861.

21. Highlights of the 2010 American Heart Association Guidelines for CPR and ECC 2010; 11-18.

22. Trinkle RM, Flabouris A (2011) Documenting Rapid Response System afferent limb failure and associated patient outcomes. Resuscitation 82: 810-814.

23. Sandroni C, Cavallaro F (2011) Failure of the afferent limb: a persistent problem in rapid response systems. Resuscitation 82: 797-798.

24. Tintinalli J, Stapczynski J, John Ma, David Cline, Rita Cydulka, et al. (2011) Tintinalli's Emergency Medicine: A Comprehensive Study Guide, Seventh Edition 39-44; 44-49; 76-69.

25. A New Order for CPR, Spelled C-A-B: American Heart Association Guidelines (Oct. 18, 2010) The American Heart Association is re-arranging the ABCs of cardiopulmonary resuscitation (CPR) in its 2010 American Heart Association Guidelines for Cardiopulmonary Resuscitation and Emergency 2010; 28-77.

26. Mary Fran Hazinski, Ricardo Samson, Steve Schexnayder (2010) American Heart Association Handbook of Emergency Cardiovascular Care for Healthcare Providers (AHA Handbook of Emergency Cardiovascular Care) 17-29.

27. Highlights of the 2010 American Heart Association Guidelines for CPR and ECC. http://static.heart.org/ eccguidelines/pdf/ucm_317350.pdf. Accessed Dec. 11, 2010.

28. An archive University Clinical Centre of Kosovo Emergency Clinic of, Pristina 2010-2011.
Citation: Lenjani B, Pallaska K, Hyseni K, Karemani N, Bunjaku I, et al. (2014) Cardiac Arrest - Cardiopulmonary Resuscitation. Gen Med (Los Angel) 2: 131. doi: $10.4172 / 2327-5146.1000131$ 